Referencia para citar este artículo: Rey-Galindo, M. J. (2019). El Abogado del Niño. Representación de una garantía procesal básica. Revista Latinoamericana de Ciencias Sociales, Niñez y Juventud, 17(1), 35-46. doi:https://dx.doi.org/10.11600/1692715x.17101

\title{
El Abogado del Niño. Representación de una garantía procesal básica*
}

\author{
MARIANA JoSEFINA REY-GALINDO ** \\ Profesora Universidad Nacional de Tucumán, Argentina.
}

\section{Artículo recibido en junio 13 de 2018; artículo aceptado en octubre 24 de 2018 (Eds.)}

Resumen (analítico): este trabajo recoge un aspecto de la investigación regional iniciada en el año 2015, impulsada por Organismos Estatales Argentinos, en la que participé como ayudante de campo. El objetivo fue conocer y explicar de qué manera se manifiesta el derecho del niño y la niña a participar en los asuntos judiciales, principalmente Juzgados de Familia. Las vertientes exploradas fueron: a) ser oídos, $y$ b) contar con abogado.

La autora se circunscribe a la provincia de Tucumán durante el período 2016/2017. La metodología fue descriptiva y exploratoria. Se hizo un relevamiento cuantitativo y un análisis cualitativo de los datos. Los resultados muestran que las garantías legales se cumplen parcialmente y que el acceso a la justicia para la infancia y la adolescencia es un modelo para armar entre todos los operadores del sistema judicial.

Palabras clave: derechos del niño, derecho a la justicia, niñez y juventud (Tesauro de Ciencias Sociales de la Unesco).

\section{A Child's Lawyer: Representation of a basic procedural guarantee}

- Abstract (analytical): This study focuses on an aspect of regional research initiated in 2015 promoted by Argentinian government organizations that I participated in as a Field Assistant. The objective was to raise awareness of and explain how a child can exercise their right to participate in legal matters, mainly in the Family Court. The areas covered by this area of research included: a) the right to be heard, and b) the right to have a lawyer.

The study focused on children requiring legal representation in the province of Tucumán during the 2016/2017 period. The methodology used was descriptive and exploratory. A quantitative survey and qualitative analysis of the data was conducted. The results show that legal requirements are partially met and that access to justice for children and adolescents is a model to be followed by all operators of the legal system.

Key words: Children's rights, right to justice, childhood and youth (Unesco Social Science Thesaurus).

Este artículo de reflexión presenta los resultados de la investigación denominada «El acceso a la justicia de niños, niñas y adolescentes en la provincia de Tucumán. Sujetos de derechos y actores del proceso. La importancia de sus opiniones y el derecho a participar con abogado». La misma inició en diciembre de 2016 y concluyó en agosto del año 2017 en el marco del «Programa de Investigación Posdoctoral en Ciencias Sociales, Infancias y Juventud, en la línea Contextos, Practicas Políticas y Políticas Publicas», de la Red Clacso de Posgrados. Acta No 071 de fecha 03/08/2018. Área de conocimiento: Derecho. Subárea de conocimiento: Derechos Humanos.

** Doctora en Derechos Humanos, expedido por AAU — American Androgogy University — Honolulu, Hawai, USA. Profesora en la Universidad Nacional de Tucumán y en la Universidad San Pablo T. Jueza de Familia y Sucesiones del Centro Judicial de Monteros, Tucumán. Orcid: 00000003-4637-3956. Correo electrónico: marianareygalindo@gmail.com 


\section{O advogado da criança. Representação de uma garantia processual básica}

- Resumo (analítico): Este trabalho inclui um aspecto da pesquisa regional iniciada em 2015 , promovida pelas Organizações Estaduais da Argentina, na qual participei como assistente de campo. $O$ objetivo foi conhecer e explicar como se manifesta o direito da criança de participar de questões judiciais, principalmente tribunais de família. As áreas exploradas foram: a) ser ouvida e b) ter advogado.

O autor limita-se à província de Tucumán durante o período de 2016/2017. A metodologia foi descritiva e exploratória. Uma pesquisa quantitativa e uma análise qualitativa dos dados foram feitas. Os resultados mostram que as garantias legais são parcialmente cumpridas e que o acesso à justiça para crianças e adolescentes é um modelo a ser armado entre todos os operadores do sistema judicial.

Palavras-chave: direitos da criança, direito à justiça, infância e juventude (Thesaurus de Ciências Sociais da Unesco).

-1. Preliminar: ¿Qué se entiende por niño? ¿Cuál es la función de un abogado? -2. Introducción. -3. El niño como sujeto de derechos. -4. La garantía procesal del artículo 12 de la Convención de los Derechos del Niño: ser oído, que su opinión sea tenida en cuenta y participar con representante, y su acogimiento por el derecho nacional argentino. $\mathbf{- 5}$. El rol del abogado del Niño como garantía procesal. Pertinencia y relevancia. -6. Aplicación de la norma: teoría y práctica. -7. Algunas reflexiones finales. -Lista de referencias.

\section{Preliminar: ¿Qué se entiende por niño? ¿Cuál es la función de un abogado?}

Considero que para poder comprender hacia donde se encaminan las próximas líneas de ese trabajo, es imprescindible comenzar por el principio, es decir, saber de qué hablamos cuando hablamos de niños y niñas, y a qué nos referimos cuando decimos «tener abogado».

Como respuesta al primer punto en cuestión: cuando me refiera a niños, niñas y adolescentes ${ }^{1}$ lo haré a partir de la Convención de los Derechos del Niño² (Naciones Unidas, 1989), texto legal que en el art. $1^{\mathrm{o}}$ establece: «Para los efectos de la presente Convención, se entiende por niño o niña todo ser humano menor de dieciocho años de edad, salvo que, en virtud de la ley que le sea aplicable, haya alcanzado antes la mayoría de edad».

En contestación a la segunda inquietud, según el Diccionario Jurídico:

La palabra «abogado» proviene del latín advocatus, y en su exacta acepción, designa a un perito en derecho que se dedica a defender en juicio, por escrito o por palabra, los derechos o los intereses de los litigantes y también a dar opiniones o emitir dictamen sobre las cuestiones o puntos legales que se les consulte. (Valletta, 2006, p. 11)

Además el mismo Diccionario refiere que cuando un abogado ejerce su profesión en pleito, no está ejerciendo simplemente su derecho a trabajar, sin que ejerce una función pública como auxiliar de la justicia, asegurando, además, a sus clientes el principio cardinal de defensa en juicio, derecho fundamental y básico. (Valletta, 2006, p. 11)

\section{Introducción}

En la historia legislativa respecto a los Derechos de la Infancia y la Adolescencia, existe un hito trascendental que se comparte con otros países del mundo, especialmente en Latinoamérica y el

1 En adelante NNyA.

2 En adelante $\mathrm{CDN}$. 
Caribe, y es la suscripción de la CDN. No obstante, anticipo que este artículo se circunscribe solo a la República Argentina, lugar donde se hiciera la investigación de la autora, y dentro de ese país, a una sola región, que es la provincia de Tucumán.

En 1990 Argentina suscribe a la CDN, momento a partir del cual adquiere vigencia legal, y, en consecuencia, adquiere fuerza operativa para el derecho interno nacional (Ley 23 849). Luego, en el año 1994, el país determina una reforma constitucional de trascedente envergadura, en la cual la CDN fue incorporada - junto con otros diez Tratados Internacionales de Derechos Humanos - a la Constitución Nacional, obteniendo el mismo rango de supremacía jurídica. A partir de allí, se produce lo que se conoce como el proceso de constitucionalización del derecho privado, pues la recepción formal y sustancial de aquellos documentos de Derechos Humanos, generó un cambio rotundo en la visión de todo el sistema legal.

A partir de la constitucionalización o humanización del derecho privado, se produce un cambio paradigmático, con dos ejes centrales: $1^{\circ}$ ) se entiende a la persona como sujeto de derechos $\mathrm{y}, 2^{\circ}$ ) el ámbito de protección de la persona excede los sistemas nacionales para instalarse en el ámbito internacional. De ese modo, se evidencia el fracaso de los modelos jurídicos tradicionales del Siglo $\mathrm{XX}$, donde situaban al individuo como objeto de derechos y al Estado como garante de la paz social.

En este contexto es que, con la revalidación e incorporación constitucional de la CDN a la Constitución Nacional, se instaura un cambio fundamental en materia de reconocimientos de derechos para los NNyA, quienes se convierten en «sujetos de derechos» abandonando el modelo aquel de «objetos de tutelas».

Desde esta concepción, se forzó al Sistema Reglamentario interno y las normas infraconstitucionales, a su necesaria e inherente reformulación general para poder guardar coherencia con aquel proceso de «humanización del derecho privado». Es así, que en el año 2005, se sanciona la Ley Nacional 26061 por la cual se instituye el Sistema de Protección Integral de Niños, Niñas y Adolescentes (Congreso de la Nación Argentina, 2005). Con esta herramienta legal se aspira logrado por cierto - a adaptar el derecho interno al derecho internacional y constitucional moderno. Texto jurídico que en su art. 27 concentra las garantías procesales a favor de la infancia y adolescencia y, en consecuencia, confirma el derecho constitucional del niño o niña a ser oído u oída y participar en los procesos judiciales con patrocinio letrado. Todo ello remitiéndose a los Instrumentos de Derechos Humanos incorporados por la Constitución Nacional.

Posteriormente, en el año 2015, se produce la reforma en materia de Derecho Civil, logrando la unificación en una sola pieza jurídica: el Código Civil y Comercial Común (Ley 26 994). Ese Digesto, no solo defiende al niño o la niña como sujeto titular de derechos, sino que agrega explícitamente en su art. 26, la posibilidad de ejercer esos derechos por medio de un abogado de su confianza.

A partir de 1994, y aún más con las sucesivas innovaciones legislativas, los Tribunales se vieron obligados — aún permanecen en deuda - a lograr un proceso de implementación de esas reformas para la protección de los derechos y las garantías judiciales a favor de la infancia y la adolescencia. Primordialmente, para que se pueda visibilizar a los NNyA como sujetos plenos de derechos, luego, para reconocer que ese individuo en minoría de edad, tiene la capacidad de ejercer esos derechos, conforme su edad y madurez. En síntesis, dos caras de la misma moneda: titularidad de derechos/ ejercicio de derechos.

Con el énfasis legal que logra la implementación del Sistema de Protección Integral, irrumpe una nueva mirada, un modo distinto de abordar los conflictos que involucran a NNyA, reconociendo en ellos el derecho a gozar de las mismas garantías procesales que cualquier otro sujeto ante los asuntos llevados a los estrados judiciales.

Este artículo centra su atención en el derecho consagrado tanto por el art. 12 de la CDN, el art. 27 de la Ley 26061 y el art. 26 del Código Civil y Comercial, a que el niño o la niña sea oído u oída en todos los asuntos que le conciernen, a que su opinión sea tenida en cuenta, y principalmente al derecho a participar activamente con asistencia letrada (abogado/abogada) en los procesos judiciales donde, de una manera u otra, se encuentre involucrado. 
Iniciar una práctica judicial tan especial, distinta a aquella en la cual los funcionarios judiciales no tenían costumbre de manejarse con NNyA y, mucho menos, considerar y enterarse de lo que ellos pensaran, aun cuando actuaran en su nombre, produjo en el medio forense una suerte de desconcierto generalizado.

Si bien el derecho a opinar y ser oído se impuso por la CDN desde el año 1994, los tribunales argentinos, en su práctica judicial, no tienen uniformidad de criterios en cuanto a las formas, la oportunidad y las condiciones procesales de llevar a cabo el acto de oír a los NNyA. Mucho menos - y es lo que este trabajo demuestra - cómo se implementa la figura del Abogado del Niño y la determinación de su rol en el proceso judicial.

\section{El niño como sujeto de derechos}

En el trabajo «La doctrina de Protección Integral y los Derechos Civiles, Económicos, Sociales y Culturales de la Infancia en la Provincia de Jujuy, a la vista del Derecho Internacional de los Derechos Humanos» (Rey-Galindo, 2015) propuse (re)pensar (en base a la frecuente afirmación de los adultos de que «el niño es el ciudadano del futuro»), si en el mundo de la ciudadanía, el niño o la niña será algo solo en el futuro. Algunas preguntas que surgieron en aquella oportunidad fueron: ¿qué es el niño o la niña hoy?, ¿es un ser sin identidad social?, ¿sin un yo propio?, ¿sin la autonomía de los sujetos sociales? (p. 1754)

A estas alturas, podemos afirmar que definitivamente las cosas con los niños y las niñas han cambiado. En los modernos sistemas jurídicos no es aceptado el «come y cállate», «siéntate y obedece», «porque soy tu padre sé lo que te digo», y otras expresiones del estilo. El modelo tradicional del niño como objeto de tutela cambió rotundamente, para admitir que hoy los NNyA son sujetos de derechos y pueden ejercerlos personal y directamente.

La CDN hace un reconocimiento inequívoco y sin precedentes en tratados de Derechos Humanos de los NNyA como titulares de derechos, y subraya la dignidad como personas. Esta Convención se centra en el carácter social y jurídico del niño o niña. En la actualidad, los NNyA son pensados como personas completas, capaces de desarrollar todos sus derechos. Georgina Morales (2008) afirma en su trabajo «El derecho del niño a ser oídos en el ámbito judicial»:

Tampoco son pequeños adultos, son personas en procesos de desarrollo que tienen deberes y responsabilidades, como todos tenemos en la medida de sus proporciones, asunto que está íntimamente relacionado con el proceso educativo: el niño, la niña, el o la joven pueden expresarse pero deben aprender a respetar a los demás, a escuchar y a intercambiar sus ideas. (p. 95)

Como lo sostuve en el trabajo de mi autoría mencionado anteriormente, vemos que en la CDN, la niñez y la adolescencia no es una expresión de anhelos a futuro, por el contrario a partir de sus normas se construye el presente de esos sujetos que son considerados «ciudadanos». Ser ciudadanos es tener un yo, una autonomía de sujeto social, además del yo animal que poseen los seres vivos y del yo trascendental que poseen los seres éticos, ser ciudadanos es tener un yo social de los que bien en sociedad y se relacionan en un mundo de reglas en que hay derechos y obligaciones (Rey-Galindo, 2015, p. 1754).

En esta dirección, Gabriela Magistris (2016) sostiene que esto posibilitó pensar al niño como un sujeto al que debe protegerse y no solo como el «ápice de una familia» (p. 273). Agrega Magistris que «el derecho del niño o niña a ser oído en las intervenciones de los organismos de protección de derechos, se ha impuesto como un gran progreso en relación al patronato, donde [...] la autoridad estaba enteramente colocada del lado del juez de menores» (pp. 272-273).

Así es que, desde el derecho internacional se realiza un claro reconocimiento a la condición especial que tienen los NNyA como ciudadanos, debido a su situación de personas en desarrollo y crecimiento. Este reconocimiento se acompaña del 
establecimiento de un deber por parte de los Estados de protección especial y reforzada hacia ellos y ellas, del cual se deriva el principio del interés superior del niño que supone la obligación de los Estados de adoptar decisiones y de priorizar las intervenciones que favorezcan la realización de los derechos de los NNyA, así como su protección. (Comisión Interamericana de Derechos Humanos, 2017)

Como consecuencia de ello, se reconoce la autonomía progresiva de los NNyA para ejercer los derechos por sí mismos, de acuerdo a la edad y la madurez. Los Estados están obligados a adaptar las normas, las políticas y las prácticas para reconocer y apoyar a los NNyA en el ejercicio autónomo de sus derechos y a tomar sus decisiones.

\section{La garantía procesal del artículo 12 de la Convención de los Derechos del Niño: ser oído, que su opinión sea tenida en cuenta y participar con representante, y su acogimiento por el derecho nacional argentino}

Entre los derechos que consagra la CDN a favor de la infancia y la adolescencia, se encuentra el derecho a ser oído, a opinar y a que su voz sea considerada por los operadores judiciales. Lo que jurídicamente se conoce como «la garantía del debido proceso» según el Art. 8 del Pacto de San José. El eje central de las garantías procesales a favor de los NNyA se encuentra configurado en la CDN, cuyo texto dispone:

1. Los Estados Partes garantizarán al niño que esté en condiciones de formarse un juicio propio el derecho de expresar su opinión libremente en todos los asuntos que afectan al niño, teniéndose debidamente en cuenta las opiniones del niño, en función de la edad y madurez del niño. 2. Con tal fin, se dará en particular al niño oportunidad de ser escuchado, en todo procedimiento judicial o administrativo que afecte al niño, ya sea directamente o por medio de un representante o de un órgano apropiado, en consonancia con las normas de procedimiento de la ley nacional. (Art. 12)

Esta norma establece dos derechos básicos de los NNyA: primero, el derecho a ser oído y expresarse libremente en todo asunto que le concierne; y, segundo, la aplicación de esa regla, en procesos judiciales donde el niño o niña se encuentre involucrado — según grado y madurez-y con la posibilidad de que participe por medio de representantes o de un órgano especial, acorde sistemas jurídicos internos. Se trata de un derecho humano que goza de jerarquía constitucional y que debe valorarse como un acto sustancial del proceso, jamás como una mera formalidad no esencial.

Todo ello conforma lo que para los adultos se conoce como «el derecho a un proceso justo y la inviolabilidad de la defensa en juicio», privilegio que se dijo antes, se instituye en la Convención Americana sobre los Derechos Humanos (Organización de los Estados Americanos, 1969).

Este trabajo se concentra en el derecho a la participación del niño o niña con abogado en los procesos que lo afecten, y de su amparo o acogimiento en el derecho interno argentino. Igualmente, se propone realizar un planteo crítico de las posiciones adultocéntricas que aún persisten en un sistema que se precia y auto percibe de ser respetuoso de los derechos de los NNyA.

Desde el año 2005, en las leyes de la República Argentina, con la publicación de la Ley 26061 , y con ella la instauración del Sistema de Protección Integral a NNyA, irrumpió un nuevo modelo para abordar los conflictos que involucran a los NNyA. Con esta ley se incorpora la figura del abogado del niño, en el art. 27. Esta norma dispone:

Garantías mínimas de procedimiento judiciales o administrativos. Los Organismos del Estado deberán garantizar a las niñas, niños y adolescentes en cualquier procedimiento judicial o administrativo que los afecte, además de todos aquellos derechos contemplados en la Constitución Nacional, la Convención sobre los Derechos del Niño, en los tratados internacionales ratificados por la Nación Argentina y en las leyes que en su consecuencia se dicten, los siguientes derechos y garantías: a) A ser oído ante la autoridad competente cada vez que así lo solicite la niña, niño o adolescente; b) A que su opinión sea tomada 
primordialmente en cuenta al momento de arribar a una decisión que lo afecte; c) $A$ ser asistido por un letrado preferentemente especializado en niñez y adolescencia desde el inicio del procedimiento judicial o administrativo que lo incluya. En caso de carecer de recursos económicos el Estado deberá asignarle de oficio un letrado que lo patrocine; d) A participar activamente en todo el procedimiento; e) A recurrir ante el superior frente a cualquier decisión que lo afecte. (Ley 26 061)

Más tarde, en el año 2015, la misma figura es añadida en el art. 26 del Código Civil y Comercial: Ejercicio de los derechos por la persona menor de edad. La persona menor de edad ejerce sus derechos a través de sus representantes legales. No obstante, la que cuenta con edad y grado de madurez suficiente puede ejercer por sí los actos que le son permitidos por el ordenamiento jurídico. En situaciones de conflicto de intereses con sus representantes legales, puede intervenir con asistencia letrada. La persona menor de edad tiene derecho a ser oída en todo proceso judicial que le concierne así como a participar en las decisiones sobre su persona. Se presume que el adolescente entre trece y dieciséis años tiene aptitud para decidir por sí respecto de aquellos tratamientos que no resultan invasivos, ni comprometen su estado de salud o provocan un riesgo grave en su vida o integridad física. Si se trata de tratamientos invasivos que comprometen su estado de salud o está en riesgo la integridad o la vida, el adolescente debe prestar su consentimiento con la asistencia de sus progenitores; el conflicto entre ambos se resuelve teniendo en cuenta su interés superior, sobre la base de la opinión médica respecto a las consecuencias de la realización o no del acto médico. A partir de los dieciséis años el adolescente es considerado como un adulto para las decisiones atinentes al cuidado de su propio cuerpo. ${ }^{3}$ (Ley 26 994)

Como se desprende claramente de esas disposiciones, el primer elemento que debe «valorar, considerar y apreciar» una persona o autoridad para tomar decisiones en relación a un NNyA es su opinión sobre la situación planteada.

A partir de los postulados normativos, la opinión del niño o la niña constituye un factor determinante para la aplicación de la Ley y, en consecuencia, para motivar las decisiones del juez o jueza. También es válido dejar aclarado que, motivar las sentencias basados en la opinión del NNyA, significa que el magistrado «toma en cuenta las manifestaciones del NNyA» para resolver (legalmente) el caso, despejando y apartando todo tipo de antojos infundados, no solo de los y las personas menores de edad, sino de las partes adultas del mismo proceso. Esta actividad intelectiva, opera con otro criterio rector en temas de infancia y adolescencia, que es «interés superior del niño». (Naciones Unidas, 1989)

Desde esta perspectiva, en el marco del Sistema de Protección Integral, parecería casi imposible determinar cuál es el mejor interés de un NNyA en un caso en concreto, sin antes conocer su opinión. De hecho, considero que es así en las prácticas cotidianas de familias, escuelas y comunidades. Pues bien, si esto ocurre en los ámbitos no estatales, con mayor razón debería ocurrir y convertirse en una regla general en los procedimientos judiciales que les afectan directamente a los niños y niñas, y donde suelen tomarse decisiones de mucha trascendencia sobre sus vidas. En este sentido, Juan Rafael Perdomo concluye que:

Abstenerse ilegítimamente o ilegalmente de oír la opinión de un NNyA en un procedimiento administrativo o judicial comporta una violación de un derecho humano y de un principio garantista con jerarquía constitucional, lo que acarrea por regla, la nulidad y la reposición de la causa al estado en que se garantice el ejercicio de tal derecho. (2008, p. 34)

En la misma línea, Aida Kemelmajer de Carlucci afirma que el niño es titular de derechos propios, que puede ejercer aún contra sus padres, porque hoy se le concede al niño «un lugar» distinto, diferente pero no menos respetable que el del adulto. Y en consecuencia, si el menor es sujeto de derechos y no objeto del mismo, es la

3 Las cursivas me pertenecen. 
justicia la que debe aproximar a la realidad lo que prometen las normas constitucionales al niño, ya que las decisiones judiciales cumplen una función docente al emitir un mensaje a la sociedad. (2012, p. 168)

Para concluir, cabe entonces la pregunta: ¿por qué un NNyA tendría que expresar su opinión por medio de un abogado? La respuesta viene no solo de las normas antes citadas, sino, además de las Reglas de Brasilia para el Acceso a la Justicia de las Personas en condiciones de Vulnerabilidad (2008) aprobadas en la XIV Cumbre Judicial Iberoamericana donde se establecen las pautas para el Acceso a la Justicia a las personas en Situación de Vulnerabilidad. En ese documento internacional, un NNyA es una persona vulnerable:

Toda vez que se consideran en condiciones de vulnerabilidad aquellas personas que, por razones de edad, genero, estado físico o mental, o por circunstancias sociales, económicas étnicas, y/o culturales, se encuentran en especiales dificultades para ejercitar con plenitud ante el sistema de justicia los derechos reconocidos por el ordenamiento jurídico. (Cumbre Judicial Iberoamericana, 2008)

Las reglas 64 y 65 de dicho documento internacional establecen la necesidad de la asistencia técnica antes y durante el acto judicial:

Previa a la celebración del acto: Se procurará la prestación de asistencia por personal especializado (profesionales en Psicología, Trabajo Social, intérpretes, traductores u otros que se consideren necesarios) destinada a afrontar las preocupaciones y temores ligados a la celebración de la vista judicial. Durante el acto judicial: Cuando la concreta situación de vulnerabilidad lo aconseje, la declaración y demás actos procesales se llevarán a cabo con la presencia de un profesional, cuya función será la de contribuir a garantizar los derechos de la persona en condición de vulnerabilidad. (Cumbre Judicial Iberoamericana, 2008)

En algunos casos, se apela a la presencia de un «referente emocional» de personas en situación de vulnerabilidad. Los NNyA tienen sus propios intereses, pueden ser comunes o no al de sus progenitores, y su propia voz en los procesos judiciales, puede y debe ser escuchada sin la intermediación de sus padres. Según las normas citadas, un NNyA tiene derecho a participar activamente de los asuntos judiciales que los involucre, y tiene derecho a elegir un abogado. Evangelina Suárez (2017), afirma que

el abogado del niño tiene a su cargo su defensa técnica, entendida como la posibilidad de designar un letrado de su confianza o de recibir asistencia técnica de oficio, para lo cual debe interpretar los deseos y aspiraciones del menor y obrar en consecuencia. Este abogado tiene a su cargo el patrocinio de intereses y derechos definidos por el propio interesado, sin sustituir su voluntad. (p. 3)

En conclusión, el abogado del niño o niña, viene a darle la voz en un proceso donde generalmente solo se escuchan las perspectivas adultas. El niño y la niña con su abogado, exige que se garantice la total vigencia de sus derechos en cualquier proceso donde ellos intervengan, independientemente del patrocinio letrado con el que cuenten sus propios padres y/o terceros intervinientes.

\section{El rol del Abogado del Niño como garantía procesal. Pertinencia y relevancia}

El CDN sostiene, en la Observación General No 5, que «para que los derechos cobren sentido, se debe disponer de recursos efectivos para reparar sus violaciones». Esta exigencia aparece está sobrentendida en la CDN, y se la refiere en otros documentos internacionales. El Estado debe tener en cuenta la situación particular de cada NNyA y trabajar para que tengan acceso a procedimientos eficaces: suministro de información, asesoramiento legal, promoción y autopromoción y acceso a la asistencia letrada.

Desde esa perspectiva, no basta que se reconozca a los NNyA como sujetos de derechos, sino que se permita que los ejerzan activamente, y que los Estados otorguen la posibilidad del acceso a la justicia de modo seguro y protegido. Es decir, que los mecanismos de la justicia deben ser 
accesibles, adecuados, y eliminando toda formalidad u otras limitaciones y/o exigencias que restrinjan injustificadamente la capacidad de los NNyA de acceder a la justicia.

Es, justamente, en este aspecto donde se pone de manifiesto la pertinencia y relevancia de la figura del Abogado del Niño, y el ejercicio de defensas técnicas en procesos judiciales que afecten al niño o la niña (sus clientes). En consonancia con esa perspectiva, Cháves-Luna (2015) afirma que en lo tocante a los principios en procesos de familia encuentra atinada la invocación al interés superior del niño en el artículo 706 del CCCN y la prescripción del art. 707 del mismo cuerpo normativo cuando concede derecho a los niños, las niñas y adolescentes a participar y ser oídos en todos los procesos que los afecta directamente y que su opinión debe ser tenida en cuenta y valorada según su grado de discernimiento y la cuestión debatida. (p. 91)

Esta figura se diferencia claramente de la representación que puedan tener los padres (pues a éstos les caben las funciones derivadas de la responsabilidad parental de los hijos e hijas menores de edad) de las que pueda tener el Asesor de Menores, que es un mandato constitucional. Su rol es promover la participación de la justicia para garantizar la legalidad de los intereses generales de la sociedad en coordinación con las demás autoridades de la Republica (jueces), en procesos donde se involucran personas menores de edad (art. $120 \mathrm{CNA}$ ) — pero en ningún caso es el representante legal del NNyA.

En el sistema legal argentino, se cuenta con tres normas claves por las que incorpora la figura del Abogado del Niño: a) Art. 12 de la CDN (incorporada a la Constitución Nacional desde 1994), b) Art. 27 de la Ley 26 061, y c) Art. 26 del Código Civil y Comercial Común.

A partir de allí, el Estado argentino ratifica el derecho de los NNyA a participar en los procesos que los involucra - aun en contra de sus padres - por medio de su abogado o abogada. Lo que implica la garantía del «debido proceso y la inviolabilidad de la defensa en juicio» (Organización de los Estados Americanos, 1969).

La figura del Abogado del Niño es de gran utilidad para la materialización del paradigma de la niñez, en tanto sujetos activos de derechos, constructores de su propia ciudadanía, surgiendo así como el garante del ejercicio de los derechos de la infancia y adolescencia.

Ahora bien, ese derecho implica, además, la posibilidad de «elegir al profesional» que quiera llevar adelante su juicio y, como contrapartida, la posibilidad de revocar el patrocinio cuando dicho profesional se aparte de los mandatos o deseos propios del niño o niña. La elección puede ser consecuencia de la confianza en ese profesional, o bien de la especificidad en el tema involucrado: derecho a las imágenes subidas a las redes sociales por los progenitores; acciones de filiación en temas de adopción y la participación en la elección de una familia; medias cautelares en el marco de la violencia intrafamiliar, etc.

Pero todo eso hace al modelo del Sistema de Protección Integral de los NNyA, y ya no pueden ser tratados como meros destinatarios de políticas y acciones asistenciales ejecutadas por el Estado o por otros mayores.

Tal como sostiene Videtta (2017), a pesar del respeto que adquirió, legislativamente, la figura del abogado en los últimos años, su puesta en práctica ha sido polémica y dificultosa (p. 6). Aún se discute sobre, ¿cómo se elige el Abogado del Niño?, ¿quién paga los honorarios?, ¿en qué tipo de procesos podría participar o es válido en todos?, ¿a partir de qué edad el niño o niña puede elegir un abogado?, ¿cuáles serían los mecanismos de remoción del patrocinante?, etc., cuestiones todas ellas válidas, pero que de ningún modo pueden afectar el cumplimiento y la efectividad de una norma vigente. De ningún modo, esos cuestionamientos pueden demorar, aplazar o denegar la participación de los NNyA con sus abogados o abogadas, en los procesos en los que ellos y ellas decidan designarlos/as. Destaca Videtta (2017), que

el derecho a participar activamente de los procesos que lo afecten es una garantía procesal del NNA. Y en tanto garantía, resulta facultad de aquéllos designar un abogado y realizar actuaciones procesales, es decir que es un derecho y no un deber o una carga procesal. Empero, en tanto derecho tiene que tener la posibilidad de ejercerlo. (pp. 6-7) 
Esto llevó a que varias provincias dicten normas para la creación de registros de Abogados del Niño, y eventualmente la reglamentación del ejercicio profesional. Otras provincias no la tienen, como es el caso de Tucumán. Sin embargo, la figura del Abogado del Niño es expresa, está en la ley, es un derecho del niño o niña. Es una obligación de los operadores judiciales aceptar su intervención.

Autores locales, como Mónica Assandri (2015), han sostenido que la «defensa técnica» es una garantía esencial e integrante del debido proceso legal. Assandri afirma que el derecho de NNyA «de acceder a la justicia con patrocinio letrado hace a su interés superior» (p. 2461) ya que implica asegurarles el pleno goce de sus derechos sobre los principios de igualdad, libertad, autonomía y capacidad progresiva. El derecho «a comparecer a juicio patrocinado por su abogado», no puede ser limitado por ley, por resolución judicial ni política pública alguna.

Cualquier discusión secundaria respecto del ejercicio o registración de esta figura, deberá postergarse para otros espacios: académicos, de política institucional, de protocolos, etc., sin que ninguno de esas cuestiones se convierta en un elemento disuasorio del derecho a la participación activa del niño o niña en el proceso junto con su abogado.

El abogado del niño o niña debe garantizar, junto a todo el aparato judicial, el interés superior de los niños y niñas teniendo en cuenta los elementos señalados por Rony Eulalio López-Contreras (2015): la expresión y los deseos de los niños, niñas y adolescentes; la búsqueda de un entorno familiar y social que favorezca el desarrollo de su personalidad; y, la valoración de un futuro favorable.

\section{Aplicación de la norma: teoría y práctica}

En las tablas 1 y 2 se muestra un aspecto de la investigación realizada sobre la implementación de la figura del Abogado del Niño en los procesos judiciales en el fuero de familia, en aquellos casos donde sus intereses pudieran estar no solo en juego, sino contrapuestos con el de los adultos involucrados en el expediente.

Los datos que se muestran, corresponden a la cantidad de procesos y NNyA asistidos con sus propios abogados o abogadas, en el período comprendido entre enero de 2014 y abril de 2017. Ese período temporal tiene un sentido específico, puesto que corresponde al momento entre la sanción del Código Civil y Comercial Común (Congreso de la Nación Argentina, 2014) y la fecha de conclusión de esta investigación (abril de 2017). La recopilación de los datos se realizó a través de pedidos formales, consentidos y suscriptos por los dos Colegios de Abogados de la provincia de Tucumán (Colegio de Abogados de Tucumán y Colegio de Abogados del Sur) y en la Oficina de Mesa de Entrada Civil del Poder Judicial de Tucumán. Además, se realizaron entrevistas con magistrados y funcionarios del Fuero de Familia y Sucesiones y con profesionales que tuvieron actuación como abogados del niño o niña. La entrevista fue una estrategia de la investigación cualitativa, y para la recolección de datos. Las mismas fueron pactadas previamente con cada uno de los/las participantes y con cuestionarios prediseñados.

Los procesos judiciales elegidos, responden a los que específicamente el niño o niña podría intervenir activamente en ejercicio de sus derechos, y por medio de asistencia letrada: Abogado del Niño. Se toman los datos de los dos circuitos judiciales existentes hasta entonces: Capital y Concepción (el $3^{\circ}$ circuito judicial en materia familiar, entra en funcionamiento en Mayo de 2017).

4 La vigencia de este Código data del 1 de agosto de 2015. 
Tabla 1. Cantidad de expedientes en Capital (enero 2014/abril 2017)

\begin{tabular}{|c|c|c|}
\hline TIPO PROCESAL & $\begin{array}{l}\text { CANTIDAD DE } \\
\text { CASOS }\end{array}$ & $\begin{array}{l}\text { CANTIDAD DE NNyA } \\
\text { REPRESENTADOS POR } \\
\text { ABOGADOS }\end{array}$ \\
\hline Filiación & 762 & 1 \\
\hline Guardas & 518 & 0 \\
\hline Adopciones & 180 & 0 \\
\hline Alimentos & 4255 & 2 \\
\hline Régimen comunicacional (Visitas) & 399 & 6 \\
\hline Cuidado Personal del niño o niña (custodia) & 4200 & 1 \\
\hline Restitución Internacional & 26 & 1 \\
\hline $\begin{array}{l}\text { Medidas cautelares por violencia familiar } \\
\text { (alimentos, custodia, cuidados personales, } \\
\text { comunicación con el otro progenitor, etc.) }\end{array}$ & 5037 & 6 \\
\hline
\end{tabular}

Tabla 2. Cantidad de expedientes en Concepción (enero 2014/abril 2017)

\begin{tabular}{|c|c|c|}
\hline TIPO PROCESAL & CANTIDAD DE CASOS & $\begin{array}{l}\text { CANTIDAD DE NNYA } \\
\text { REPRESENTADOS POR } \\
\text { ABOGADOS }\end{array}$ \\
\hline Filiación & 324 & 1 \\
\hline Guardas & S/registros & 0 \\
\hline Adopción & $\mathrm{S} /$ registros & 0 \\
\hline Régimen Comunicacional (Visitas) & 402 & 0 \\
\hline Cuidado personal del niño o niña (custodia) & 109 & 0 \\
\hline Restitución Internacional & $\mathrm{S} /$ registros & 0 \\
\hline $\begin{array}{l}\text { Medidas cautelares por violencia familiar } \\
\text { (alimentos, custodia, cuidados personales, } \\
\text { comunicación con el otro progenitor, etc.) }\end{array}$ & 1721 & 1 \\
\hline
\end{tabular}

De esa información, surge que, en la jurisdicción de Capital, en un total de 15377 causas ingresadas en ese período, por Mesa de Entrada del Fuero de Familia (exclusivamente en los tipos procesales indicados), solo en diecisiete causas un NNyA tuvo oportunidad de ser representado por un abogado o abogada, en temas en donde la ley prevé la participación con abogados como garantía mínima procesal básica a favor de la infancia y la adolescencia. En el caso de Concepción, de un total de 2556, solo en dos se cuenta con la participación del Abogado del Niño.

Sin perjuicio de ello, corresponde por la ética académica de esta autora, aclarar que con posterioridad al período investigado (enero 2014-mayo 2017), y como consecuencia de la exhibición pública de esos resultados en un Congreso Internacional, la práctica judicial se dispuso de mejor manera para la aceptación de este derecho de los NNyA, y, en la actualidad, en el caso del circuido capital ya se cuenta con cuarenta y dos abogados y abogadas en procesos de familia y un solo abogado en un proceso penal, según información proporcionada por el Colegio de Abogados de la Capital.

Es así que, la misma Corte Suprema de Justicia de Tucumán (2017), tuvo oportunidad de pronunciarse en un caso en concreto y dijo: 
Teniendo especialmente en cuenta la capacidad progresiva del niño -según criterios de madurez y desarrollo evolutivo-, corresponde examinar la alternativa de la designación de un abogado del niño, figura contemplada explícitamente en el art. 27 de la Ley 26061 de Protección integral de derechos de las niñas, niños y adolescentes, cuando expresa «Los Organismos del Estado deberán garantizar a las niñas, niños y adolescentes en cualquier procedimiento judicial o administrativo que los afecte, además de todos aquellos derechos contemplados en la Constitución Nacional, la Convención sobre los Derechos del Niño, en los tratados internacionales ratificados por la Nación Argentina y en las leyes que en su consecuencia se dicten, los siguientes derechos y garantías: [...] c) A ser asistido por un letrado preferentemente especializado en niñez y adolescencia desde el inicio del procedimiento judicial o administrativo que lo incluya. En caso de carecer de recursos económicos el Estado deberá asignarle de oficio un letrado que lo patrocine. [...] Sobre la cuestión del abogado del niño, numerosos precedentes jurisprudenciales recurrieron a esta figura en supuestos semejantes (conf. CNCiv., sala B, in re «L. N. A. c. Z. M. s/ art. 250 C.P.C. Incidente de familia», de fecha 06/12/2013, La Ley Online, AR/JUR/94918/2013. Sup. Corte Just. Mendoza, sala 1 ${ }^{a}, 8 / 4 / 2014$, «DYNAF s/ solicita medida conexa s/ inc.», LL del 26/5/2014, p. 10). Por ello, y teniendo en cuenta las circunstancias especificas del caso de autos y la necesidad de satisfacer íntegramente las garantías de las personas involucradas, la cuestión merece ser analizada con prontitud. ${ }^{5}$

\section{Algunas reflexiones finales}

Según los resultados obtenidos se observó que las garantías procesales establecidas en el Art. 12 de la CDN y sus concordantes normas nacionales, decididamente son de cumplimiento parcial. Según el criterio del Juez o la Jueza que entienda en la causa, será el destino que tenga la intervención del niño o niña en el proceso conjuntamente con su abogado. Por lo tanto, el acceso a la justicia para la infancia y la adolescencia, como un derecho político, económico y social, sigue siendo un modelo para armar entre todos los (adultos) operadores del sistema judicial.

Aunque el paradigma para la infancia y la adolescencia haya cambiado sustancialmente (de objeto de tutela a sujeto de derechos) aún hoy cuesta visibilizar a los/as NNyA como sujeto activo de derechos. Sigue existiendo una deuda en la práctica judicial con la infancia y la adolescencia. Aún hoy existen, no solo prejuicios y estereotipos adultos, sino que enfrenta un desafío corporativo que lo lleva a desterrar múltiples barreras y elementos disuasorios en el acceso a la justicia para los NNyA. Por este motivo, es necesario proponer nuevas líneas de investigación sobre esta materia, tendientes a que, con la experiencia que se haya obtenido en la asistencia jurídico-procesal a niños, niñas y adolescentes en los procesos judiciales, se logren diseños específicos de protocolos de actuación para el abogado del niño.

Como contracara de la investigación que he realizado, surge un elemento inusitado y maravilloso que me permite concluir que aún con barreras, incluso con resistencia, y contra toda adversidad del sistema adultocéntrico, ya son varios los/as NNyA quienes realzando su voz en un proceso judicial, exigen, demandan y reivindican el cambio que les pertenece y de los que son protagonistas.

\section{Lista de referencias}

Assandri, M. (2015). Principios y Reglas Generales del proceso ante el fuero familia. En Tratado de Derecho de Niños, Niñas y Adolescentes. Tomo III (pp. 2447-2463). Buenos Aires: Abeledo Perrot.

5 Las cursivas me pertenecen. 
Comisión Interamericana de Derechos Humanos. (2017). Hacia la garantía efectiva de los derechos del niño, niña y adolescente: Sistemas Nacionales de Protección. Recuperado de: www.oas.org/ es/cidh/informes/pdfs/NNA-GarantiaDerechos.pdf.

Congreso de la Nación Argentina. (2005). Ley de Protección Integral de los Derechos de las Niñas, Niños y Adolescentes. Recuperada de:

http://servicios.infoleg.gob.ar/infolegInternet/anexos/110000-114999/110778/norma.htm.

Congreso de la Nación Argentina. (2014). Código Civil y Comercial Común. Recuperada de: http:// servicios.infoleg.gob.ar/infolegInternet/verNorma.do?id=235975. Argentina.

Corte Suprema de Justicia de Tucumán. (2017). Sentencia 987. Recuperado de: www.justucuman. gov.ar.

Cumbre Judicial Iberoamericana. (2008). Reglas de Brasilia para el Acceso a la Justicia de las Personas en condiciones de Vulnerabilidad. Recuperado de: www.acnur.org/fileadmin/scripts/ doc.php?file=fileadmin/Documentos/BDL/200.

Cháves-Luna, L. S. (2015). El Abogado del Niño. Buenos Aires: Tribunales Ediciones.

Kemelmajer de Carlucci, A. (2012). El derecho constitucional del niño a ser oído. Revista de Derecho Privado y Comunitario, (II), pp. 157-170.

López-Contreras, R. E. (2015). Interés superior de los niños y niñas: definición y contenido. Revista Latinoamericana de Ciencias Sociales, Niñez y Juventud, 13(1), pp. 51-70. doi:10.11600/16927 $15 x .1311210213$.

Magistris, G. (2016). El derecho de la infancia en la era de los derechos. (Tesis doctoral no publicada). Universidad de Buenos Aires, Buenos Aires, Argentina. Recuperada de: https://www.aacademica. org/gabrielamagistris/26.pdf.

Morales, G. (2008). El derecho del niño a ser oído en el ámbito judicial. En G. Morales (Coord.), La garantía de los niños, niñas y adolescentes a opinar y ser oídos en los procedimientos judiciales (pp. 95-140). Caracas: Acea.

Naciones Unidas. (1989). Convención de los Derechos del Niño. Recuperado de: http://www.un.org/ es/events/childrenday/pdf/derechos.pdf.

Organización de los Estados Americanos. (1969). Convención Americana de los Derechos Humanos (Pacto de San José). Recuperado de: https://www.oas.org/dil/esp/tratados_b-32_convencion_ americana_sobre_derechos_humanos.htm.

Perdomo, J. R. (2008). El derecho del niño a ser oído y a opinar en la Convención sobre los Derechos del Niño y la Ley Orgánica para la Protección de los Niños, Niñas y Adolescentes. En G. Morales (Coord.), La garantía de los niños, niñas y adolescentes a opinar y ser oídos en los procedimientos judiciales (pp. 15-45). Caracas: Acea.

Rey-Galindo, M. J. (2015). La doctrina de Protección Integral y los Derechos Civiles, Económicos, Sociales y Culturales de la Infancia en la Provincia de Jujuy, a la vista del Derecho Internacional de los Derechos Humanos. En Tratado de Derecho de Niños, Niñas y Adolescentes. Tomo II (pp. 2447-2463). Buenos Aires: Abeledo Perrot.

Suárez, E. (2017). El abogado del niño. Buenos Aires: Thomson Reuters.

Valletta, M. L. (2006). Diccionario jurídico. Florida: Valletta Ediciones.

Videtta, C. (2017). Los niños, niñas y adolescentes como sujetos del proceso. A propósito de un precedente que cierra la brecha entre el discurso que emerge del corpus iuris de la niñez y la adolescencia y la práctica cotidiana. Buenos Aires: Thomson Reuters. 